\title{
Leukaemia and reproductive outcome among nurses handling antineoplastic drugs
}

\author{
Torsten Skov, Birgit Maarup, Jørn Olsen, Mikael Rørth, Hanna Winthereik, Elsebeth Lynge
}

\begin{abstract}
During the past decades conclusive evidence has accumulated that alkylating antineoplastic drugs (ADs) can cause cancer, most notably acute non-lymphocytic leukaemia, and that most ADs are reprotoxic. Studies on health workers handling ADs have shown significantly increased risks for miscarriages (two studies) and malformations (two studies). The present study monitored the risk for cancer and adverse reproductive outcome among Danish nurses handling ADs. No increased risks were found for miscarriages, malformations, low birth weight, or preterm birth among the offspring of nurses handling ADs during pregnancy. The sex ratio was normal. The relative risk (RR) for leukaemia was significantly increased $(10.65)$ but based on only two cases, one of acute myeloblastic and one of chronic myeloid leukaemia. From the available exposure data occupational exposures to ADs were apparently higher in the studies that have reported increased risks for miscarriages and malformations than in the present one. Regarding reproductive outcome the study gives some confidence that the safety measures which were implemented in the oncology departments around 1980 can protect the health personnel against adverse effects of $A D s$
\end{abstract}

Danish Cancer Registry, Institute of Cancer Epidemiology, Danish Cancer Society, Rosenvængets Hovedvej 35, Box 839, 2100 København $\emptyset$, Denmark

T Skov, E Lynge

Department of Oncology, KAS Herlev, Herlev Ringvej 75, 2730 Herlev, Denmark

B Maarup

Institute of Social Medicine, University of Århus, Hoegh-Guldbergsgade 8, 8000 Århus C, Denmark J Olsen

Department of Oncology ONK, Rigshospitalet, Blegdamsvej 9, 2100 København Ø, Denmark M Rørth

Frederikssund Hospital, Dybendal, Frederikssundsvej 30, 3600 Frederikssund, Denmark $\mathrm{H}$ Winthereik on reproduction. As the study is as yet the only negative one in a well protected setting, it should be followed up by other studies of well protected health personnel handling ADs. The findings concerning the leukaemia risk, although based on small numbers, encourage larger studies.

Antineoplastic drugs (ADs) constitute a heterogenous group of chemicals that share the ability to inhibit tumour cell growth while exerting tolerable toxicity on normal body cells. They have been used in the treatment of malignant diseases for more than $\mathbf{4 0}$ years, and the number of cancers eligible for medical treatment has been steadily expanding.

During the past decade conclusive evidence has accumulated that treatment of malignant as well as non-malignant diseases with alkylating ADs carries a substantial risk of second malignancies, most notably acute non-lymphocytic leukaemia. ${ }^{1}$ Bladder cancer caused by the alkylating agent cyclophosphamide was first shown among patients treated with immunosuppressive drugs for non-malignant diseases. ${ }^{2-4}$ In animal studies, all tested $\mathrm{ADs}$ have shown teratogenicity or embryotoxicity. ${ }^{156}$

Two studies of nurses occupationally exposed to ADs showed relative risks (RRs) for miscarriages of $2 \cdot 30$ (95\% confidence interval $(95 \% \mathrm{CI}) 1 \cdot 20-4 \cdot 39)$ and $1 \cdot 70(95 \%$ CI $1 \cdot 0-2 \cdot 8)$ respectively. ${ }^{78}$ No safety measures was taken during drug preparation in these study groups. Two other studies have shown increased risks for congenital malformations among health personnel handling ADs; a Finnish study found an odds ratio (OR) of $4.7(p=0.02)$ for malformations in the offspring of nurses handling $\mathrm{ADs},{ }^{9}$ and a Canadian study found eight malformations compared to 4.05 expected $(p=0.05)$ in offspring of nurses and doctors who had administered ADs early in pregnancy..$^{10}$ No information on safety measures was given in these studies. There were no clusters of specific malformations.

We have carried out a study of leukaemia and nonHodgkin's lymphoma among physicians who have worked with ADs. ${ }^{11}$ The RR for leukaemia was $2 \cdot 85$ (95\% CI 0.51-16.02). No other studies of cancer risk related to occupational exposure to ADs exist. 
The exposure of health personnel to ADs has been assessed in several studies including air pollution measurements and measurements of biological effects such as urine mutagenicity or cytogenetic effects in lymphocytes. Falck et al found significantly higher mutagenicity in urine from oncology nurses than from controls when no safety measures were taken. ${ }^{12}$ After implementation of such measures mutagenicity decreased. ${ }^{13}$ Subsequently, several groups have studied urinary mutagenicity in nurses and pharmacists handling ADs. Positive results have been found, ${ }^{14-18}$ but the use of laminar air flow hoods and other safety precautions have been associated with negative findings. ${ }^{14-1618}$ except in one study. ${ }^{19}$ Four studies of oncology nurses have found increased sister chromatid exchange and chromosomal aberrations in lymphocytes from exposed nurses compared with those from control groups, ${ }^{19-22}$ but negative studies have also appeared. ${ }^{2324}$

Awareness regarding safe handling of ADs surfaced around 1980. Subsequently, guidelines for health workers handling these drugs were issued by authorities in several countries including Denmark, but great concern exists about the possible adverse health effects of occupational exposure. The purpose of this study was to monitor the risk for cancer and adverse reproductive outcomes among health workers handling ADs in Denmark.

\section{Material and methods}

The study group included female nurses who potentially had been exposed to ADs through their work in one of the five 'old' oncology departments in Denmark. Four of these have operated throughout the whole period in which nurses have taken part in the preparation or administration of $\mathrm{ADs}$ - that is, since the early 1970s. The last one started in 1976. An internal control group of about double the number of potentially exposed nurses was established by identifying nurses employed in the same period in other departments in the same hospitals, assumed to be comparable with the oncology departments with regard to lifting, shiftwork, and general work strain.

All nurses were identified by means of records kept by the administration at the hospitals. The identity was verified in the central population register. Thirty seven persons could not be identified and were excluded from the study. Included in the cohort thereafter were 1282 nurses from oncology departments and 2572 from control departments. The criterion of exposure was preparation or administration of ADs. The head nurses of the oncology departments provided data about preparation and administration of the drugs for individual cohort members. In two of the departments old lists existed of the weekly number and type of treatments given in the departments. Since all day-shift nurses had participated equally in this work the individual exposure could be quantified as number of treatments prepared, or administered, or both a week. In two other departments, the head nurses (assisted by senior staff members) indicated the exposure semiquantitatively as high, medium, low, and no exposure. In the last (and smallest) of the oncology departments exposure could only be given as yes or no.

For the analyses, the quantitative assessments were aggregated with the semiquantitative by grouping four or more treatments a week as high exposure, two to three treatments a week as medium, one treatment a week as low, and none as no exposure. Observations with yes or no information only were not included in the semiquantitative analyses. Information about safety measures was collected by interview with head nurses and senior staff members.

\section{IDENTIFICATION OF OUTCOME}

The outcomes of interest (miscarriages, congenital malformations, birth weight, gestational age and prematurity, and cancer) were identified through record linkages by means of the unique 10 digit identification number possessed by all Danes. All children born by the study nurses during 1973-88 were identified in the Danish birth register, which has been computerised since 1973. Multiple births were excluded. Remaining were 286 children born to mothers employed in oncology departments during pregnancy and 770 children born to mothers employed in reference departments during pregnancy (table 1). With only five stillbirths in the two groups together, this outcome was not analysed.

Data about miscarriages came mainly from the hospital discharge register, which has operated since 1977. Induced abortions were added from the register of induced abortions, and a few miscarriages were added from the register of congenital malformations, which has operated since 1983. Eighteen abortions were identified among nurses employed in oncology departments during pregnancy and 65 abortions among nurses employed in control departments during pregnancy in the period 1977-88 (table 1).

Malformations were identified by linkage with the hospital discharge register, the Danish birth register, and the register of congenital malformations. Sixteen children with malformations were identified among the offspring of nurses employed in oncology departments during pregnancy and 43 among the offspring of nurses employed in control departments during pregnancy in the period 1973-88.

Incident cancers in the group of oncology nurses were identified in the Danish cancer registry until 31 December 1987. The Danish cancer registry has operated since 1943. ORs of miscarriages were computed as the compared groups of miscarriages 
Table 1 Reproductive outcomes in 275 nurses working in oncology departments and 765 nurses working in reference departments during pregnancy

\begin{tabular}{|c|c|c|}
\hline & $\begin{array}{l}\text { Mother employed in oncology } \\
\text { department during pregnancy }\end{array}$ & $\begin{array}{l}\text { Mother employed in reference } \\
\text { department during pregnancy }\end{array}$ \\
\hline \multicolumn{3}{|l|}{ Miscarriages (1977-88): } \\
\hline All pregnancies & 18 & 65 \\
\hline First pregnancies only & 12 & 44 \\
\hline \multicolumn{3}{|l|}{ Malformations $(1973-88)$ : } \\
\hline All pregnancies & 16 & 43 \\
\hline First pregnancies only & 10 & 35 \\
\hline \multicolumn{3}{|l|}{ Induced abortions (1977-88): } \\
\hline All pregnancies & 45 & 126 \\
\hline \multirow{2}{*}{\multicolumn{3}{|c|}{ Ectopic pregnancies (1977-88): }} \\
\hline & & \\
\hline All pregnancies & 5 & 14 \\
\hline First pregnancies only & 5 & 12 \\
\hline \multicolumn{3}{|l|}{ Births $(1977-88)$ : } \\
\hline All pregnancies & 213 & 604 \\
\hline First pregnancies only & 161 & 461 \\
\hline \multicolumn{3}{|l|}{ Births (1973-88): } \\
\hline All pregnancies & 286 & 770 \\
\hline First pregnancies only & 226 & 618 \\
\hline
\end{tabular}

divided by all other pregnancies (births, stillbirths, induced abortions, and ectopic pregnancies). Odds ratios of malformations were computed as the compared groups of malformations divided by all other births. Age standardised point estimates and $95 \%$ confidence intervals ( $95 \%$ CIs) were computed with the EGRET software package, as were the logistic regression analyses. Birth weight was analysed with multiple linear regression modelling using the SAS software package.

The outcome of two pregnancies in the same woman may not be independent and it is usually considered correct to include only one pregnancy per woman in any given analysis. Therefore, the analyses of miscarriages and malformations were done both on material restricted to the first employed pregnancy of any study nurse and on material including all employed pregnancies of the study nurses. Because the point estimates differed little, in some instances only the unrestricted results are presented to preserve power. The material available for analysis of birthweight, gestational age, and sex ratio was larger, and for these outcomes the restricted analyses are presented.

Standardised incidence ratios (SIRs) were calculated with PYRS software for cancer in the group of nurses who had worked in oncology departments and had handled ADs, with Danish national rates as the standard. The internal reference group was not used for comparison in the analysis of cancer because much precision would have been lost. To ensure comparability with the standard rates a person in the study group could be included with more than one cancer case, provided they were at different sites. A person was considered exposed from first date of exposure until death, emigration, or end of follow up on 31 December 1987, whichever came first. In all the analyses observations with missing values for one or more of the relevant variables were excluded.

The study was approved by the Danish Data Protection Agency and the ethical committees. The oncology nurses were informed through their journal.

\section{Results \\ MISCARRIAGES}

The crude OR for miscarriages among those handling ADs during pregnancy compared with the control group employed in other departments was $0 \cdot 76$ (95\% CI $0 \cdot 38-1 \cdot 43)$. Inclusion of all nurses employed in oncology departments, whether exposed or not, changed the OR to $0.78(95 \% \mathrm{CI}$ $0.43-1.37)$. Standardisation according to the age of the mother changed the risk estimate from 0.76 to 0.74 only (table 2 ).

The analysis by exposure level showed a significantly increased risk among those in the low exposure category, and, if anything, an inverse dose-response relation (table 3). The ORs for the periods before and after implementation of safety measures (before 1980 $v 1980$ or later) differed little (table 2), but the precision of the point estimates was low, especially for the period before 1980 .

\section{MALFORMATIONS}

The crude OR for malformations among those handling ADs during pregnancy compared with the control group employed in other departments was $1.02(95 \%$ CI $0.47-2 \cdot 06)$. Inclusion of all nurses employed in oncology departments, whether exposed or not, changed the OR to $1.00(95 \%$ CI $0 \cdot 52-1 \cdot 85)$. Standardisation according to the age of the mother changed the risk estimate from 1.02 to 
Table 2 Odds ratios for miscarriages, malformations, and low birth weight among nurses handling ADs during pregnancy compared with nurses working in reference departments during pregnancy

\begin{tabular}{|c|c|c|c|c|c|c|}
\hline & \multicolumn{2}{|c|}{$1973 / 7-88$} & \multicolumn{2}{|c|}{$1973 / 7-9$} & \multicolumn{2}{|c|}{$1980-8$} \\
\hline & $O R$ & $(95 \% C I)$ & $O R$ & $(95 \% C I)$ & $O R$ & $(95 \% C I)$ \\
\hline $\begin{array}{l}\text { Miscarriages }(1977-88) \\
\text { All pregnancies } \\
\text { First pregnancies only }\end{array}$ & $\begin{array}{l}0 \cdot 74 \\
0 \cdot 80\end{array}$ & $\begin{array}{l}(0 \cdot 40-1 \cdot 38) \\
(0 \cdot 38-1 \cdot 69)\end{array}$ & $1 \cdot 10$ & $\underline{(0 \cdot 19-4 \cdot 56)}^{-}$ & $\frac{0.70}{-}$ & $\underline{(0 \cdot 31-1 \cdot 44)}^{-}$ \\
\hline $\begin{array}{l}\text { Malformations (1973-88): } \\
\text { All pregnancies } \\
\text { First pregnancies only }\end{array}$ & $\begin{array}{l}0.99 \\
0.70\end{array}$ & $\begin{array}{l}(0 \cdot 50-1 \cdot 96) \\
(0 \cdot 29-1 \cdot 70)\end{array}$ & $0 \cdot 20$ & $(0 \cdot 00-1 \cdot 32)$ & 1.57 & $(0.64-3.58)$ \\
\hline $\begin{array}{l}\text { Low birth weight }(\leqslant 2500 \mathrm{~g})(1973-88) \text { : } \\
\text { First children only }\end{array}$ & 1.06 & $(0.42-2 \cdot 67)$ & 0.94 & $(0 \cdot 20-4 \cdot 45)$ & $1 \cdot 13$ & $(0 \cdot 36-3 \cdot 54)$ \\
\hline
\end{tabular}

ORs adjusted for age.

0.99 only (table 2 ). There were no clusters of specific malformations.

The risk estimate for the high exposure category was highest (OR 1.36), followed by the category of pregnancies in which the nurse had been employed in an oncology department but had not handled ADs (table 4). The number of miscarriages in each exposure category was small. The OR for the periods before the implementation of safety measures was lower than after, but again the precision of the risk estimate was low (table 2).

BIRTH WEIGHT AND GESTATIONAL AGE

The mean birth weight among children liveborn to mothers handling ADs during pregnancy was $3397 \mathrm{~g}$ compared with $3455 \mathrm{~g}$ in the control group.

An exposure may affect the birth weight by shortening the duration of gestation or by decreasing the intrauterine growth rate. In the present material, the mean gestational age for liveborn children of mothers in the exposed group was 39.64 weeks compared with 39.69 weeks in the control group. Thus the duration of gestation was practically identical between the groups.

To adjust for possible confounding, the growth rate was analysed in a multiple linear regression model that, as well as the exposure, included the available data on known risk factors-namely, gestational age, pregnancy order, and the sex of the child. These three factors showed the expected associations. Handling ADs during pregnancy was associated with a $56 \mathrm{~g}$ lowering of the birth weight, but the association was not significant at the $5 \%$ level (table 5).

In an alternative analysis of birth weight, low birth weight was defined as $2500 \mathrm{~g}$ or less and normal birth weight as more than $2500 \mathrm{~g}$. The OR for low birth weight according to this definition among those exposed to ADs was 1.06 (95\% CI 0.42-2.67) (table 2). The risk estimates for the periods before and after implementation of safety measures (earlier than 1980 $v 1980$ or later) differed little.

\section{SEX RATIO}

A small preponderance of boys was found in the exposed group with an OR for being a boy of 1.12 $(95 \%$ CI $0 \cdot 79-1 \cdot 61)$. No trend was seen with increasing exposure (data not shown).

\section{CANCER}

A total of 794 nurses handling ADs contributed 5636 person-years at risk. The number of observed cancer cases (14) was close to the expected (11.69) corresponding to an RR of 1.20 (table 6 ). The only significantly increased site was lymphatic and haematopoietic tissue where the increased risk was due to two cases of leukaemia, giving an RR for leukaemia of $10 \cdot 65(95 \%$ CI 1.29-38.5).

One of the patients with leukaemia had prepared five treatments of $\mathrm{ADs}$ a week during the period 1974-7. In 1977 she developed Hodgkin's disease (stage $2 \mathrm{~b}$ ) and had radiation therapy exclusively. A

Table 3 Miscarriages among nurses employed in oncology departments during pregnancy compared with nurses working in reference departments during pregnancy 1977-88

\begin{tabular}{|c|c|c|c|c|}
\hline Exposure group & $\begin{array}{l}\text { No of } \\
\text { miscarriages }\end{array}$ & $\begin{array}{l}\text { No of other } \\
\text { pregnancies }\end{array}$ & $O R^{\star}$ & $(95 \% C I)$ \\
\hline $\begin{array}{l}\text { Reference group } \\
\text { Not handling ADs in oncology department } \\
\text { Low exposure group } \\
\text { Intermediate exposure group } \\
\text { High exposure group }\end{array}$ & $\begin{array}{r}65 \\
3 \\
4 \\
3 \\
5\end{array}$ & $\begin{array}{r}744 \\
49 \\
12 \\
49 \\
110\end{array}$ & $\begin{array}{l}1 \cdot 00 \\
0 \cdot 67 \\
3 \cdot 74 \\
0 \cdot 71 \\
0 \cdot 49\end{array}$ & $\begin{array}{l}\text { reference } \\
(0 \cdot 20-2 \cdot 26) \\
(1 \cdot 17-12 \cdot 0) \\
(0 \cdot 22-2 \cdot 36) \\
(0 \cdot 19-1 \cdot 26)\end{array}$ \\
\hline
\end{tabular}

^Estimated by unconditional logistic regression model including age. 
Table 4 Congenital malformations in the offspring of nurses employed in oncology departments compared with nurses working in reference departments during pregnancy 1973-88

\begin{tabular}{lllll}
\hline Exposure group & No of malformations & No of births & OR $^{\star}$ & $(95 \%$ CI) \\
\hline Reference group & 43 & 770 & $1 \cdot 00$ & reference \\
Not handling ADs in oncology department & 4 & 60 & $1 \cdot 21$ & $(0 \cdot 42-3 \cdot 49)$ \\
Low exposure group & 0 & 28 & -0.66 & $(0 \cdot 15-2 \cdot 81)$ \\
Intermediate exposure group & 2 & 52 & $1 \cdot 36$ & $(0 \cdot 59-3 \cdot 14)$ \\
High exposure group & 7 & 91 & & \\
\hline
\end{tabular}

^Estimated by unconditional logistic regression model including age.

few months later she developed acute myeloblastic leukaemia. The other case of leukaemia (chronic myeloid) was diagnosed in 1987 in a nurse who had prepared five treatments a week for four months in 1982.

\section{Discussion}

The overall risk estimates were not increased for miscarriages, malformations, low birth weight, or preterm birth among the offspring of nurses handling ADs during pregnancy. The sex ratio was normal. The RR for leukaemia was significantly increased, but this was based on only two cases, one of acute myeloblastic and one of chronic myeloid leukaemia.

No information was available about possible confounding factors such as tobacco smoking and alcohol consumption for adverse reproductive outcome. Instead of collecting this information, we chose to identify a control group as similar to the study group as possible except for the exposure to $\mathrm{ADs}$. One advantage of this method is that it is likely to avoid confounding, not only from known risk factors but also from any unknown risk factors. The control group of nurses employed in the same hospitals is identical to the study group with regard to social group and employment, and is probably comparable for work load and smoking and drinking habits. The

Table 5 Gestational age and birth weight in the offspring of nurses handling $A D s$ in oncology departments compared with

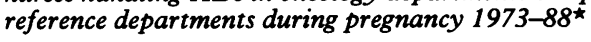

\begin{tabular}{lll}
\hline & $\begin{array}{l}\text { Employed in } \\
\text { reference } \\
\text { department }\end{array}$ & $\begin{array}{l}\text { Handling } \\
\text { ADs in } \\
\text { oncology } \\
\text { department }\end{array}$ \\
\hline \multicolumn{1}{c}{$\begin{array}{l}\text { Mean birth weight (g) } \\
\text { Mean gestational age (weeks) }\end{array}$} & 3455 & 3397 \\
& 39.69 & 39.64 \\
$\begin{array}{l}\text { Gestational age in weeks } \\
\text { (g per week) }\end{array}$ & 191 & \\
$\begin{array}{l}\text { Male sex } \\
\text { Pregnancy order }>1\end{array}$ & $122 \mathrm{~g}$ & $\mathrm{p}<10^{-4}$ \\
Handling ADs & $151 \mathrm{~g}$ & $\mathrm{p}<10^{-4}$ \\
$\mathrm{p}<10^{-4}$
\end{tabular}

^One pregnancy per woman. lack of any age confounding indicates that a certain degree of homogeneity between the groups was actually achieved. By identifying outcomes and exposures through registers and hospital departments respectively, we avoided a possible recall bias, which could be a serious problem in a study in which the study subjects are conscious of the possible association between the exposure and the outcome. By identifying the control group among nurses working in the same hospitals at the same time as the oncology nurses, we aimed to avoid a selection bias that might result from different hospital admission rates between the two groups. The abortion rate in the control group was 65 of $809(8.0 \%)$; (table 1), which compares well with the rate of $8.47 \%$ for the Danish population found by Modvig. ${ }^{25}$

The study included the time before as well as after the implementation of safety measures in the Danish oncology departments. Miscarriages could be followed up, however, from 1977 only, when the hospital discharge register started, and although in principle the registration of malformations goes back until 1973 with the medical birth register, many malformations are only identified in the hospital discharge register (which has operated since 1977 only), and the registration of malformations in the period $1973-6$ is therefore less complete than afterwards. Finally, fewer nurses took part in the preparation and administration of $\mathrm{ADs}$ in the 1970s. For these reasons, the number of miscarriages and malformations available for analysis before 1980 was limited, and the lack of consistent differences between the risk estimates for miscarriages and malformations before and after 1980 should not lead to the conclusion that no increased risks existed in the unprotected setting before 1980 .

The overall risk estimates for miscarriages and malformations, which are then mainly estimating the risk in the well protected setting after 1980, had acceptable precision, and some confidence in the lack of excess risks for adverse reproductive outcome in this period can also be gained from the consistency between the findings for all outcomes, and from the lack of dose-response relations.

Two studies have found increased risks for miscarriages among nurses handling ADs. A French 
Table 6 Incidence of cancer among nurses handling antineoplastic drugs in oncology departments

\begin{tabular}{|c|c|c|c|c|}
\hline Site & Obs & $\operatorname{Exp}$ & $R R$ & $(95 \% C I)$ \\
\hline All malignant neoplasms (ICD-7 140-205) & 14 & $11 \cdot 69$ & 1.20 & $(0 \cdot 65-2 \cdot 01)$ \\
\hline Lymphatic and haematopoietic tissues (ICD-7 200-205)^ & 3 & 0.56 & $5 \cdot 37$ & $(1 \cdot 11-15 \cdot 7)$ \\
\hline NHL (ICD-7 200, 202) & 0 & $0 \cdot 20$ & - & - \\
\hline Hodgkin's disease (ICD-7 201)^ & 1 & $0 \cdot 12$ & 8.35 & $(0 \cdot 21-46 \cdot 5)$ \\
\hline Multiple myeloma (ICD-7 203) & 0 & 0.05 & - & \\
\hline Leukemia (ICD-7 204)^ & 2 & $0 \cdot 19$ & $10 \cdot 65$ & $(1 \cdot 29-38 \cdot 5)$ \\
\hline Mycosis fungoides (ICD-7 205) & 0 & 0.01 & - & - \\
\hline
\end{tabular}

^One person was counted as two cancer cases, (Hodgkin's disease and acute myeloblastic leukaemia). The diagnosis of Hodgkin's disease was made a few months before the onset of leukaemia, and was treated with radiation only. This person (diagnosed 1978) had prepared around five treatments a week during 1974-7. The other person with leukaemia (chronic myeloid, diagnosed 1987) had prepared around five treatments a week for four months in 1982.

ICD-7 = International Classification of Diseases, 7 th revision.

study included nurses who on average had prepared $18 \cdot 3$ perfusions per week without safety measures. ${ }^{8}$ Thus the exposure was substantially higher than in the present study. In a Finnish study, only a few treatments a week had been prepared. This is more like the Danish situation, but no safety measures were taken. ${ }^{7}$ In the studies that have reported increased risks for malformations ${ }^{910}$ the exposure data are not sufficiently detailed to allow a comparison with the present study. Thus from the available exposure data there would not seem to be any inconsistency between the findings in these studies and the present one.

The precision of the risk estimate for leukaemia was low, although formally the risk was significantly increased. The two leukaemia cases both have some special traits, but when we compute the expected number of cases in the study group, this figure also includes the special cases such as secondary leukaemia after treatment. Finally, it should be taken into consideration that an increased $R R$ for leukaemia was indicated, although also based on small numbers, in our study of physicians handling ADs. ${ }^{11}$

Studies of patients treated with ADs have left no doubt that ADs may cause cancer and animal studies have consistently shown an adverse reproductive outcome. The exposure to ADs has been assessed in many studies, and although it has been shown that the exposure of the health personnel is smaller than the doses received by patients treated with ADs, ${ }^{15} 1820$ the study of the risk of cancer and adverse reproductive outcome among the health personnel is important for two reasons. Firstly, from the worker's protection point of view it is important to monitor the possible risk. Secondly, assessment of the effects in humans of low dose exposures to agents known to be genotoxic at high doses is important.

Regarding reproductive outcome the present study gives some confidence that the safety measures implemented in the Danish oncology departments around 1980 can protect health personnel against adverse effects of ADs on reproduction. As the study is as yet the only negative one in a well protected setting, it should be followed up by other studies of well protected health personnel handling ADs. The findings concerning the risk of leukaemia, although based on small numbers, encourage larger studies.

1 International Agency for Research on Cancer. IARC monographs on the evaluation of carcinogenic risks to humans. Pharmaceutical drugs. Vol 50. Lyon: IARC, 1989.

2 Kinlen LJ, Sheil AGR, Peto J, Doll R. Collaborative United Kingdom-Australasian study of cancer in patients treated with immunosuppressive drugs. $B M J$ 1979;2:1461-6.

3 Kinlen LJ, Peto J, Doll R. Cancer in patients treated with immunosuppressive drugs. $B M J$ 1981:282:474.

$4 \mathrm{Kinlen} \mathrm{LJ}$. Incidence of cancer in rheumatoid arthritis and other disorders after immunosuppressive treatment. Am J Med 1985;78(suppl 1A):44-9.

5 Sorsa M, Hemminki K, Vainio H. Occupational exposure to anticancer drugs- potential and real hazards. Mutat Res 1985; 154:135-49.

6 Schardein JL. Cancer chemotherapeutic agents. In: chemically induced birth defects. New York: Marcel Dekker, 1985: 467-520.

7 Selevan SG, Lindbohm M, Hornung RW, Hemminki K. A study of occupational exposure to antineoplastic drugs and fetal loss in nurses. N Engl J Med 1985;313:1173-8.

8 Stücker I, Caillard J-F, Collin R, Gout M, Poyen D, Hemon D. Risk of spontaneous abortion among nurses handling antineoplastic drugs. Scand J Work Environ Health 1990;16:102-7.

9 Hemminki K, Kyyrönen $\mathrm{P}$, Lindbohm M. Spontaneous abortions and malformations in the offspring of nurses exposed to anaesthetic gases, cytostatic drugs, and other potential hazards in hospitals, based on registered information of outcome. J Epidemiol Community Health 1985;39:141-7.

10 McDonald AD, McDonald JC, Armstrong B, et al. Congenital defects and work in pregnancy. Br J Ind Med 1988;45:581-8.

11 Skov T, Lynge E, Maarup B, Olsen J, Rørth M, Winthereik H. Risk for physicians handling antineoplastic drugs. Lancet 1990;336:1446.

12 Falck K, Gröhn P, Sorsa M, Vainio H, Heinonen E, Holsti LR. Mutagenicity in urine of nurses handling cytostatic drugs. Lancet 1979; 1 :1250-1.

13 Falck K, Sorsa M, Vainio $H$. Use of the bacterial fluctuation test to detect mutagenicity in urine of nurses handling cytostatic drugs. Mutat Res 1981;85:236-7.

14 Anderson RW, Puckett WH, Dana WJ, Nguyen TV, Theiss JC, Matney TS. Risk of handling injectable antineoplastic agents. Am J Hosp Pharm 1982;39:1881-7.

15 Bos RP, Leenaars AO, Theuws JLG, Henderson PT. Mutagenicity of urine from nurses handling cytostatic drugs, influence of smoking. Int Arch Occup Environ Health 1982; 50:359-69.

16 Nguyen TV, Theiss JC, Matney TS. Exposure of pharmacy 
personnel to mutagenic antineoplastic drugs. Cancer Res 1982;42:4792-6.

17 Rørth M, Jørgensen J, Jørgensen V, Knudsen I, Larsen JC, Munck F. Mutagenicitet i urinen hos sygeplejersker pả onkologisk afdeling. Ugeskr Laeger 1983;145:475-8.

18 Venitt S, Crofton-Sleigh C, Hunt J, Speechley V, Briggs K. Monitoring exposure of nursing and pharmacy personnel to cytotoxic drugs: urinary mutation assays and urinary platinum. Lancet $1984 ; \mathrm{i}: 74-6$.

19 Thiringer G, Granung G, Holmén A, et al. Comparison of methods for the biomonitoring of nurses handling antitumor drugs. Scand J Work Environ Health 1991;17:133-8.

20 Norppa $H$, Sorsa $M$, Vainio $H$, et al. Increased sister chromatid exchange frequencies in lymphocytes of nurses handling cytostatic drugs. Scand $J$ Work Environ Health 1980;6: 299-301.
21 Waksvik H, Klepp O, Brøgger A. Chromosome analyses of nurses handling cytostatic agents. Cancer Treat Rep 1981; 65:607-10.

22 Nikula E, Kiviniitty K, Leisti J, Taskinen PJ. Chromosome aberrations in lymphocytes of nurses handling cytostatic agents. Scand $J$ Work Environ Health 1984;10:71-4.

23 Kolmodin-Hedman B, Hartvig P, Sorsa M, Falck K. Occupational handling of cytostatic drugs. Arch Toxicol 1983; 54:25-33.

24 Barale R, Sozzi G, Toniolo $P$, et al. Sister-chromatid exchanges in lymphocytes and mutagenicity in urine of nurses handling cytostatic drugs. Mutat Res 1985;157:235-40.

25 Modvig J. Reproduktionsskader $i$ Danmark. Copenhagen: Institute of Social Medicine, University of Copenhagen, 1991.

Accepted 2 March 1992 